\title{
Non-Esterified Fatty Acids Over-Activate the TLR2/4-NF-Kb Signaling Pathway to Increase Inflammatory Cytokine Synthesis in Neutrophils from Ketotic Cows
}

\author{
Yuming Zhang ${ }^{a}$ Xiaobing $\mathrm{Li}^{\mathrm{a}}$ Haolong Zhang ${ }^{\mathrm{b}}$ Zhibo Zhao Zhicheng Peng $^{\mathrm{a}}$ \\ Zhe Wang ${ }^{\mathrm{a}}$ Guowen Liu ${ }^{\mathrm{a}}$ Xinwei $\mathrm{Li}^{\mathrm{a}}$ \\ aKey Laboratory of Zoonosis, Ministry of Education, College of Veterinary Medicine, Jilin University, \\ Changchun, ${ }^{b}$ China-Japan Union Hospital of Jilin University, Changchun, China
}

\section{Key Words}

Non-esterified fatty acids $\bullet N F-k B$ signaling pathway $\bullet$ Inflammation $\bullet$ Neutrophils

\begin{abstract}
Background/Aims: Dairy cows with clinical ketosis display a negative energy balance and high blood concentrations of non-esterified fatty acids (NEFAs), the latter of which is an important pathological factor of ketosis in cows. The aims of this study were to investigate the inflammatory status of ketotic cows and to determine whether and through what underlying mechanism high levels of NEFAs induce an inflammatory response. Methods: Proinflammatory factors and the nuclear factor kappa B (NF-KB) signaling pathway were evaluated in neutrophils from clinical ketotic and control cows, using methods including western blotting, quantitative real-time polymerase chain reaction, and enzyme-linked immunosorbent assay. In vitro, the effects of NEFAs on the NF-KB signaling pathway in cow neutrophils were also evaluated using the above experimental techniques. Results: Ketotic cows displayed low blood concentrations of glucose and high blood NEFA and $\beta$-hydroxybutyrate concentrations. Importantly, Toll-like receptor 2 (TLR2) and TLR4 expression and IKB $\alpha$ and NF-KB p65 phosphorylation levels in neutrophils (PMNs) were significantly higher in ketotic cows than in control cows, indicating over-activation of the TLR2/4-induced NF-kB inflammatory pathway in PMNs in ketotic cows. The blood concentrations of the inflammatory cytokines interleukin- 6 (IL-6), IL-1ß, and tumor necrosis factor- $\alpha$ (TNF- $\alpha$ ) were also significantly increased in ketotic cows. Interestingly, we found that NEFAs were positively correlated with proinflammatory cytokines. In vitro, after pharmacological inhibition of TLR2 and TLR4 expression in cow neutrophils, TLR2 and TLR4 expression was significantly decreased, and the phosphorylation level of NF-KB p65 was also reduced. Cow neutrophils were treated with different concentrations of NEFAs and pyrrolidine dithiocarbamate (PDTC; an NF-KB inhibitor). High concentrations of NEFAs (0.5 and $1 \mathrm{mM}$ )
\end{abstract}

Y. Zhang and X. Li contributed equally to this work.

\begin{tabular}{ll}
\hline Guowen Liu & Key Laboratory of Zoonosis, Ministry of Education, College of Veterinary Medicine, Jilin \\
and Xinwei Li & University, 5333 Xi'an Road, Changchun, 130062, Jilin (China) \\
& Tel. +86 043187836160, Fax+86 0431 87836160, E-Mail liuguowen2008@163.com, \\
& lixinwei100@126.com
\end{tabular}




\section{Cellular Physiology Cell Physiol Biochem 2018;48:827-837 \\ \begin{tabular}{l|l} 
DOI: 10.1159/000491913 & $\begin{array}{l}\text { O } 2018 \text { The Author(s). Published by S. Karger AG, Basel } \\
\text { www.karger.com/cpb }\end{array}$
\end{tabular} \\ Zhang et al.: Nefas Over-Activate the TLR2/4-NF-кB Signaling Pathway in Neutrophils}

significantly increased TLR2 and TLR4 expression, IKB $\alpha$ and NF- $\mathrm{KB}$ p65 phosphorylation levels, NF-KB p65 transcriptional activity, and IL-6, IL-1 $\beta$, and TNF- $\alpha$ synthesis in cow neutrophils. The inhibition of NF-KB by PDTC suppressed the NEFA-induced synthesis of proinflammatory cytokines. Conclusions: High concentrations of NEFAs can over-activate the TLR2/4-mediated NF-KB signaling pathway to induce the over-production of proinflammatory cytokines, thereby increasing inflammation in cows with clinical ketosis.

(C) 2018 The Author(s)

Published by S. Karger AG, Basel

\section{Introduction}

Dairy cows are more susceptible to both metabolic diseases (fatty liver and ketosis) and infectious diseases (mastitis and metritis) during the physiologic transition from late pregnancy to early lactation $[1,2]$. During this period, dairy cows often experience a state of negative energy balance that is induced by a low intake of dry matter and an increased demand for glucose to support milk production. This negative energy balance initiates fat mobilization and a subsequent increase in the blood concentration of non-esterified fatty acids (NEFAs) [3], the latter of which is an important pathological factor of metabolic and infectious diseases during the transition period [4, 5]. Clinical data have indicated that high levels of NEFAs are related to the inflammatory response in the progression of some diseases, such as mastitis and metritis, in dairy cows $[6,7]$. Ketotic cows have high blood concentrations of the inflammatory cytokines interleukin-6 (IL-6) and tumor necrosis factor- $\alpha$ (TNF- $\alpha)$ and are believed to be more susceptible to mastitis and metritis during the transition period [8].

Neutrophils (PMNs) are the main source of inflammatory cytokines. Toll-like receptors (TLRs) can recognize pathogen-associated molecular patterns and are located on the surface of innate immune cells, such as PMNs and macrophages. TLR2 and TLR4 are major pattern recognition receptors that recognize pathogenic microorganisms [9]. Recently, growing evidence has shown that NEFAs are ligands for TLR4 [10] and subsequently induce intracellular signaling, initiating nuclear factor kappa B (NF- $\kappa B)$ cascades. Normally, the

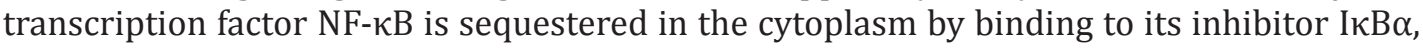
whose phosphorylation is dependent on IKK $\beta$ activity. In response to stimuli, the NF- $\kappa B$ subunit $\mathrm{p} 65$ separates from I $\mathrm{B} \alpha$ and translocates into the nucleus where NF- $\kappa \mathrm{B}$ can regulate the transcription of several inflammatory cytokine genes, such as TNF- $\alpha$, IL-6, and IL-1 $\beta$ [11].

Ketotic cows display high blood concentrations of NEFAs and an inflammatory response. PMNs are continually exposed to high blood concentrations of NEFAs in ketotic cows. NEFAs, which are regarded as inflammatory stimulants, may influence the inflammatory pathway of PMNs in dairy cows with ketosis. Therefore, the objective of this study was to examine the hypothesis that NEFAs trigger the TLR2/4-NF- $\kappa B$ signaling pathway and cause the overproduction of inflammatory cytokines in PMNs from ketotic cows. The results from this study should provide valuable information for understanding the inflammatory mechanism of ketosis in dairy cows.

\section{Materials and Methods}

\section{Animals}

The Ethics Committee on the Use and Care of Animals at Jilin University (Changchun, China) approved the study protocol. Healthy and ketotic dairy cows were selected from an 8000-cow dairy farm located in Changchun City (Jilin Province, China) to match the breed, age, milk production, and body condition scores in each group. The cows were on average calving \pm 21 days, with healthy cows having an average milk yield of $29.3 \pm 2.8 \mathrm{~kg} / \mathrm{d}$ and an average body weight of $604 \pm 22.8 \mathrm{~kg}$, and ketotic cows having an average milk yield of $26 \pm 1.5 \mathrm{~kg} / \mathrm{d}$ and an average body weight of $620 \pm 28.5 \mathrm{~kg}$. A total of 24 multiparous calving cows of second or higher lactation were allocated to two trial groups according to the clinical symptoms of ketosis and blood $\beta$-hydroxybutyrate (BHBA) concentrations. Clinical ketosis was defined as a plasma BHBA 


\section{Cellular Physiology Cell Physiol Biochem 2018;48:827-837 \\ \begin{tabular}{c|c|c|c|} 
DOI: 10.1159/000491913 & O 2018 The Author(s). Published by S. Karger AG, Basel \\
www.karger.com/cpb
\end{tabular} \\ Zhang et al.: Nefas Over-Activate the TLR2/4-NF-kB Signaling Pathway in Neutrophils}

concentration $>2.6 \mathrm{mM}$. The cows were transferred to a free-stall barn (100 lying places). They were fed a total mixed ration twice daily and were individually allocated their concentrate portion through a feeding station. They were milked once a day at 10:00. Clinical examination of the cows revealed no significant changes in temperature, pulse rate, respiratory rate, and infectious diseases.

\section{Blood biochemical parameters assay}

Blood samples were collected via coccygeal venipuncture before feeding and immediately centrifuged at $3500 \times g$ for $15 \mathrm{~min}$ at $4{ }^{\circ} \mathrm{C}$. The serum was obtained and stored at $-80{ }^{\circ} \mathrm{C}$ until analysis. Serum BHBA, NEFA, and glucose levels were determined using a Hitachi 7170 autoanalyzer (Hitachi, Tokyo, Japan) with a commercially available kit (Randox Laboratories, Crumlin, UK). The activity of alkaline phosphatase (ALP), aspartate aminotransferase (AST), alanine aminotransferase (ALT), glutamate dehydrogenase (GLDH), and gamma-glutamyl transferase (GGT) was determined using an automatic biochemistry analyzer (Sekisui Medical Co., Ltd., Tokyo, Japan) with commercially available kits (Randox Laboratories).

\section{Isolation and culture of PMNS}

PMNs were separated from blood as described by Behrendt et al [12]. Holstein cows were bled by puncture of the jugular vein and blood was collected in a 50-mL centrifuge tube (Nunc, Roskilde, Denmark) containing $0.1 \mathrm{~mL}$ heparin (Sigma-Aldrich, St. Louis, MO) as an anticoagulant. Heparinized blood was diluted in an equal amount of phosphate-buffered saline containing 0.02\% EDTA (Sigma-Aldrich), layered on Biocoll Separating Solution (Biochrom AG, Berlin, Germany), and centrifuged at $800 \times g$ for $45 \mathrm{~min}$. After removal of plasma, lymphocytes, and monocytes, the pellet was suspended in distilled water and shaken for $40 \mathrm{~s}$ to lyse erythrocytes. Osmolarity was re-adjusted immediately by adding an appropriate amount of Hanks' Salt Solution (10x; Biochrom AG). PMNs were washed twice with RPMI 1640 medium, resuspended in RPMI 1640 medium $\left(2.0 \times 10^{6}\right.$ cells $\left./ \mathrm{mL}\right)$, and incubated at $37^{\circ} \mathrm{C}$ and $5 \% \mathrm{CO}_{2}$ for at least 30 min before use.

\section{Preparation of NEFAs and treatment}

A stock NEFA solution was prepared as described previously [13]. Briefly, oleic acid (0.2175 mmol), linoleic acid $(0.0245 \mathrm{mmol})$, palmitic acid $(0.1595 \mathrm{mmol})$, stearic acid $(0.072 \mathrm{mmol})$, and palmitoleic acid $\left(0.0265 \mathrm{mmol}\right.$; all Sigma-Aldrich) were dissolved in $100 \mathrm{~mL}$ potassium hydroxide solution $(0.1 \mathrm{M})$ at $60^{\circ} \mathrm{C}$. The $\mathrm{pH}$ of the NEFA solution was adjusted to 7.4 with $1 \mathrm{M}$ hydrochloric acid. Therefore, the concentration of the stock NEFA solution was $5 \mathrm{mM}$, containing $2.175 \mathrm{mM}$ oleic acid, $1.595 \mathrm{mM}$ palmitic acid, $0.72 \mathrm{mM}$ stearic acid, $0.265 \mathrm{mM}$ palmitoleic acid, and $0.245 \mathrm{mM}$ linoleic acid. The basic medium was supplemented with $2 \%$ bovine serum albumin (BSA). NEFAs were bound to BSA, which is their natural transporter in plasma. The composition and concentration of NEFAs used in this study were chosen according to the pathological hematology standards for dairy cows with ketosis $[13,14]$.

Isolated PMNs were cultured in a 24-well plate $\left(2.0 \times 10^{6}\right.$ cells/well $)$ and incubated at $37^{\circ} \mathrm{C}$ in $5 \% \mathrm{CO}_{2}$. RPMI 1640 medium containing 10\% fetal bovine serum (HyClone, Logan, UT) and 2\% BSA (Sigma-Aldrich). The PMNs were treated for $4 \mathrm{~h}$ with $0,0.125,0.25,0.5$, and $1 \mathrm{mM} \mathrm{NEFAs,} \mathrm{with} \mathrm{or} \mathrm{without} 10 \mu \mathrm{M}$ of the NF- $\mathrm{kB}$ inhibitor pyrrolidine dithiocarbamate (PDTC; Sigma-Aldrich), $8 \mu \mathrm{M}$ of the TLR2 inhibitor CU-CPT22 (SigmaAldrich Chemie, Munich, Germany), or $10 \mu \mathrm{M}$ of the TLR4 inhibitor C34 (Sigma-Aldrich Chemie).

\section{IKKß enzyme activity detection assay}

The isolated PMNs were washed twice in ice-cold GENMED clean buffer (Reagent A; GenMed Scientifics, Inc., Wilmington, DE) for $5 \mathrm{~min}$ at $300 \times g$ at $4{ }^{\circ} \mathrm{C}$. Subsequently, the cells were treated with lysis buffer (Reagent B; GenMed Scientifics Inc.) and incubated for $30 \mathrm{~min}$ in an ice bath. The lysate was centrifuged for $5 \mathrm{~min}$ at $16,000 \times g$ at $4{ }^{\circ} \mathrm{C}$, and IKK $\beta$ activity in the supernatant was measured using a spectrophotometer and a biochemical kit (Reagent A; GenMed Scientifics, Inc.) according to the manufacturer's instructions.

Quantitative real-time polymerase chain reaction ( $q$ RT-PCR) assay

Total RNA was extracted from PMNs using RNAiso Plus (Takara Biotechnology (Dalian) Co., Ltd., Dalian, China) according to the manufacturer's instructions. RNA concentration was determined using a K5500 Micro-Spectrophotometer (Beijing Kaiao Technology Development Co., Ltd., Beijing, China). Approximately $2 \mu \mathrm{g}$ total RNA was reverse-transcribed to cDNA in $20-\mu \mathrm{L}$ reactions using 


\section{Cellular Physiology Cell Physiol Biochem 2018;48:827-837 \\ \begin{tabular}{l|l} 
DOI: 10.1159/000491913 & $\begin{array}{l}\text { O 2018 The Author(s). Published by S. Karger AG, Basel } \\
\text { www.karger.com/cpb }\end{array}$
\end{tabular} \\ Zhang et al.: Nefas Over-Activate the TLR2/4-NF-kB Signaling Pathway in Neutrophils}

PrimeScript Reverse Transcriptase (Takara Bio Co., Ltd., Kusatsu, Japan) according to the manufacturer's instructions. The primers were designed using Primer Express software (PE Applied Biosystems, Inc., Foster City, CA). TLR2: F: 5'-CAGTTTAACCCAGTGCCTTC-3', R: 5'-CTCCAACGTCTTCAGTTGCT-3', 241 bp; TLR4: F: 5'-ACTGCAGCTTCAACCGTATC-3', R: 5'-TAAAGGCTCTGCACACATCA-3', 190

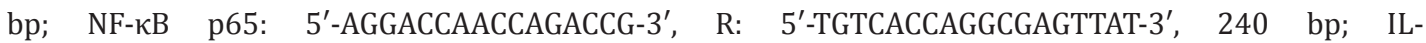
6: F: 5'-AACGAGTGGGTAAAGAACGC-3', $\quad$ R: $\quad 5^{\prime}$-CTGACCAGAGGAGGGAATGC- $3^{\prime}, \quad 144$ bp; IL-

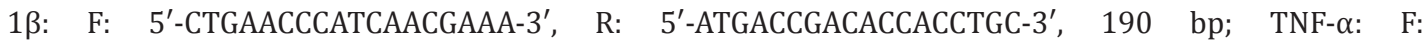
5'-CTGCCGGACTACCTGGACTAT-3', R: 5'-CCTCACTTCCCTACATCCCTAA-3', 234 bp; and $\beta$-actin: F: 5'-GCCCTGAGGCTCTCTTCCA-3', R: 5'-GCGGATGTCGACGTCACA-3', $101 \mathrm{bp}$. The mRNA expression levels were estimated by qRT-PCR analysis using FS Universal SYBR Green Real Master (Roche, Indianapolis, IN) on the 7500 Real-Time PCR System (Applied Biosystems). The conditions were as follows: $95^{\circ} \mathrm{C}$ for $3 \mathrm{~min}$, followed by 40 cycles of $95^{\circ} \mathrm{C}$ for $15 \mathrm{~s}$ and $60^{\circ} \mathrm{C}$ for $1 \mathrm{~min}$. All reactions were run in triplicate. Relative expression levels were normalized to $\beta$-actin levels.

\section{Electrophoretic mobility shift assay (EMSA)}

Nuclear proteins were extracted from PMNs by using a nuclear protein extraction kit (Sangon Biotech Co., Ltd., Shanghai, China) according to the manufacturer's instructions. The special probe recognition sequence for NF- $\mathrm{KB}$ was $5^{\prime}$-AGTTGAGGGGACTTTCCCAGGC- $3^{\prime}$. The probe was labeled with biotin by incubating at $37{ }^{\circ} \mathrm{C}$ for $1 \mathrm{~h}$ and purified using centrifugal chromatography. The binding reaction was performed using a Lightshift EMSA Optimization and Control Kit (Pierce Biotechnology, Inc., Rockford, IL) according to the manufacturer's instructions. An EMSA/gel-shift binding buffer containing $6 \mu \mathrm{g}$ nuclear extract was incubated with the biotin-labeled probe for $20 \mathrm{~min}$ at room temperature. The nuclear protein complexes were separated by electrophoresis on non-denaturing 6\% polyacrylamide Tris/borate/EDTA gels and electrotransferred onto a nylon membrane. Then, the membranes were cross-linked using a UV cross-linker (Cany Precision Instruments Co., Ltd., Shanghai, China), and the biotin-labeled probe was detected using an enhanced chemiluminescence (ECL) solution (Pierce Biotechnology, Inc.).

\section{Western blotting analysis}

Total cellular proteins and nuclear proteins were extracted using protein extraction kits (Sangon Biotech Co., Ltd.) according to the manufacturer's instructions. Sodium dodecyl sulfate-polyacrylamide gel electrophoresis separation was performed with $40 \mu \mathrm{g}$ protein per lane and with known molecular weight markers (Sangon Biotech Co., Ltd.). The proteins were then electrophoretically transferred onto a polyvinylidene fluoride membrane. The membrane was blocked with 5\% BSA in TBST buffer for 30 min at room temperature, incubated with specific antibodies to TLR2, TLR4 (Biorbyt, Cambridge, UK), NF-kBp65

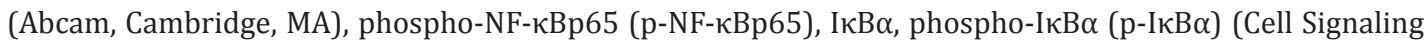
Technology, Danvers, MA), and $\beta$-actin (Santa Cruz Biotechnology, Santa Cruz, CA), and hybridized with a secondary antibody for $45 \mathrm{~min}$. Immunoreactive bands were detected with an ECL solution (Millipore, Bedford, MA). The bands were detected and analyzed using a Protein Simple Imager (Media Cybernetics, Rockville, MD).

\section{Enzyme-linked immunosorbent assay (ELISA)}

PMNs were treated with NEFAs and PDTC, respectively. Cell-free supernatants were subsequently centrifuged at $3000 \mathrm{rpm}$ for $20 \mathrm{~min}$ to extract the supernatant for the analysis of pro-inflammatory cytokines. The concentrations of IL- $1 \beta$, IL- 6 , and TNF- $\alpha$ in serum or supernatant were determined using ELISA kits (IL-1 $\beta$ : ml023753; IL-6: ml023756; TNF- $\alpha$ : ml02458; Shanghai Enzyme-linked Biotechnology Co., Ltd., Shanghai, China) according to the manufacturer's instructions.

\section{Statistical analysis}

The results are presented as the mean \pm standard error of the mean and analyzed using SPSS 19.0 software (SPSS, Inc., Chicago, IL). Analysis of variance was performed to evaluate the differences among the groups followed by the least significant difference post hoc test. A $P$-value lower than 0.05 was considered statistically significant and a $P$-value lower than 0.01 was considered highly significant. 


\section{Cellular Physiology Cell Physiol Biochem 2018;48:827-837 \\ and Biochemistry Published on $\begin{aligned} & \text { DOI: 10.1159/000491913 } \\ & \text { (c) } 2018 \text { The Author(s). Published by S. Karger AG, Basel } \\ & \text { www.karger.com/cpb }\end{aligned}$ \\ Zhang et al.: Nefas Over-Activate the TLR2/4-NF-кB Signaling Pathway in Neutrophils}

\section{Results}

\section{Energy metabolic status and inflammation levels of dairy cows with ketosis}

Blood glucose concentration was significantly lower in cows with clinical ketosis than in control cows (Table $1, P<0.05$ ). However, the blood concentrations of NEFAs and BHBA of ketotic cows were 4.37- and 6.84-fold higher than those of control cows, respectively (Table $1, P<0.05)$. Importantly, we found that the blood concentrations of the proinflammatory cytokines IL-1 $\beta$, IL-6, and TNF- $\alpha$ were significantly increased in cows with clinical ketosis (Table $1, P<0.01$ ). These results indicate that ketotic cows display high levels of inflammation. In addition, as shown in Table 1, the activity of ALP, AST, ALT, GLDH, and GGT was significantly higher in ketotic cows than in control cows $(P<0.05$ and $P<0.01)$, indicating that the ketotic cows exhibited hepatic damage.

PMNs are the main source of inflammatory cytokine synthesis and are continually exposed to high levels of NEFAs in cows with clinical ketosis. High levels of NEFAs, a pathological factor for ketosis, induce lipotoxicity [15]. Therefore, we analyzed the correlation between NEFAs and proinflammatory cytokines. As shown in Fig. 1, the levels of NEFAs had positive relationships with IL-1 $\beta\left(R^{2}=0.93\right)$, IL-6 $\left(R^{2}=0.92\right)$, and TNF- $\alpha\left(R^{2}=0.91\right)$ concentrations. These results led us to speculate that high levels of NEFAs might induce the over-activation of inflammatory pathways in neutrophils.

\section{Inflammatory TLR2/4-NF- $K B$ pathway is over-activated in PMNs from ketotic cows}

To evaluate the activation state of the inflammatory TLR2/4-NF- $\kappa B$ pathway in PMNs, the expression levels of TLR2, TLR4, and NF- $\kappa B$ were detected by western blotting and qRTPCR. The mRNA and protein levels of TLR2 and TLR4 in PMNs were significantly higher in ketotic cows than in control cows (Fig. 2A, B, D; $P<0.01$ ). The mRNA level of NF- $\kappa B$

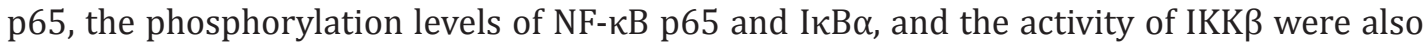
significantly increased in ketotic cows (Fig. 2D, C, E; $P<0.01$ ). To further investigate the changes in inflammatory pathways, the mRNA expression levels of IL- $1 \beta$, IL- 6 , and TNF- $\alpha$ were detected in PMNs using qRT-PCR. The mRNA expression levels of IL-1 $\beta$, IL- 6 , and TNF- $\alpha$ were markedly higher in PMNs from ketotic cows than in PMNs from control cows (Fig. 2F; $P$ $<0.01$ ). Taken together, these results indicate that the inflammatory TLR2/4-NF- $\kappa B$ pathway is over-activated in PMNs from cows with clinical ketosis, leading to the over-production of inflammatory cytokines.

\section{NEFAs activate the TLR2/4-NF- $\kappa B$ signaling pathway in cow PMNS}

The effects of NEFAs on the TLR2/4-NF- $\kappa B$ signaling pathway in cow PMNs were evaluated in vitro. The mRNA and protein levels of TLR2 and TLR4 increased gradually in the NEFA-treated groups and were significantly higher in the 0.5 and $1 \mathrm{mM}$ NEFA-treated groups than in the control group (Fig. 3A, C, E; $P<0.05$ and $P<0.01$ ). Furthermore, IKK $\beta$ activity and the phosphorylation level of I $\mathrm{B} \alpha$ were also significantly higher in the 0.5 and $1 \mathrm{mM}$ NEFA-treated groups than in the control group (Fig.

Table 1. Changes of Blood Biochemical Indexes of Ketosis Cows. The data are shown as the mean \pm SEM. ${ }^{*} P<0.05$, ${ }^{* *} P<0.01$ versus the control group

\begin{tabular}{llllll}
\hline & Control cows $(\mathrm{n}=12)$ & Ketosis cows $(\mathrm{n}=12)$ & & Control cows $(\mathrm{n}=12)$ & Ketosis cows $(\mathrm{n}=12)$ \\
\hline Glu $(\mathrm{mM})$ & $4.27 \pm 0.14$ & $2.08 \pm 0.09^{*}$ & NEFAs $(\mathrm{mM})$ & $0.29 \pm 0.08$ & $1.27 \pm 0.33^{*}$ \\
BHBA $(\mathrm{mM})$ & $0.46 \pm 0.07$ & $3.15 \pm 0.43^{*}$ & ALP $(\mathrm{U} / \mathrm{L})$ & $53.33 \pm 2.90$ & $74.33 \pm 3.17^{* *}$ \\
AST $(\mathrm{U} / \mathrm{L})$ & $80.76 \pm 13.2$ & $160.56 \pm 25.43^{* *}$ & ALT $(\mathrm{U} / \mathrm{L})$ & $24.11 \pm 7.02$ & $40.32 \pm 8.34^{*}$ \\
GLDH $(\mathrm{U} / \mathrm{L})$ & $76.89 \pm 11.25$ & $95.67 \pm 10.76$ & GGT $(\mathrm{U} / \mathrm{L})$ & $12.83 \pm 2.31$ & $36.79 \pm 5.6^{* *}$ \\
IL-6 $(\mathrm{ng} / \mathrm{L})$ & $0.44 \pm 0.02$ & $1.46 \pm 0.05^{* *}$ & IL-1 $(\mathrm{ng} / \mathrm{L})$ & $1.3 \pm 0.26$ & $6.12 \pm 0.38^{*}$ \\
TNF- $\alpha(\mathrm{ng} / \mathrm{L})$ & $61.14 \pm 3.65$ & $100.75 \pm 3.68^{* *}$ & & & \\
\hline
\end{tabular}

Fig. 1. Correlation analysis of NEFAs and proinflammatory cytokines. (A-C) The correlation coefficients between NEFAs and IL-1 $\beta$, IL- 6 and TNF- $\alpha$ were $R^{2}=0.93, R^{2}=0.92$, and $R^{2}=0.91$, respectively.

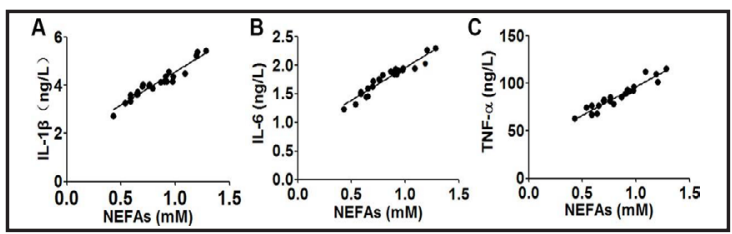


Fig. 2. TLR2/4-NF-KB inflammatory pathway was overinduced in PMNs from ketotic cows. (A) Western blotting of TLR2, TLR4, NF- $\mathrm{B}$ p65, p-NF-

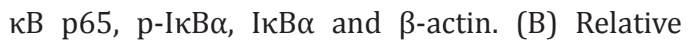
protein levels of TLR2 and TLR4 normalized to $\beta$-actin. (C) Relative protein phosphorylation levels

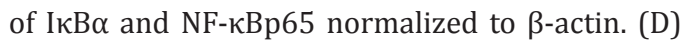
Relative mRNA expression levels of TLR2, TLR4 and NF-кBp65. (E) The activity of IKK $\beta$. (F) Relative mRNA expression levels of the proinflammatory cytokines IL-1 $\beta$, IL- 6 and TNF- $\alpha$. The data are shown as the mean \pm SEM. *, statistical significance $(\mathrm{P}<0.05){ }^{* *}$, statistical significance $(\mathrm{P}<0.01)$. The symbols $*$ and ${ }^{* *}$ indicate significant differences with the control group (no NEFAs and no PDTC), and two groups that are marked with a horizontal line are significantly different.

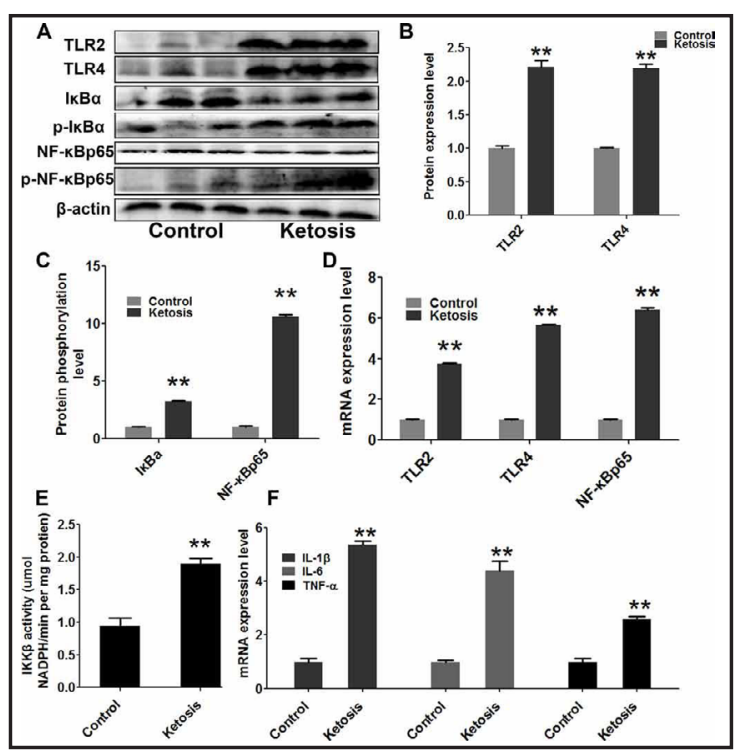

Fig. 3. NEFAs activate the NF- $\mathrm{KB}$ signaling pathway in cow PMNs in vitro. PMNs were treated with 0 , $0.125,0.25,0.5$ and $1 \mathrm{mM}$ NEFAs, $10 \mu \mathrm{M}$ PDTC and $10 \mu \mathrm{M}$ PDTC +0.5 mM NEFAs (PDTC + NEFAs). (A) Western blotting of TLR2, TLR4, I $\kappa \mathrm{B} \alpha, \mathrm{p}-\mathrm{I} \kappa \mathrm{B} \alpha, \mathrm{NF}-\kappa \mathrm{B}$ p65, p-NF-кB p65 and $\beta$-actin. (B) The activity of IKK $\beta$ in response to different concentrations of NEFAs. (C, D) Relative protein expression levels of TLR2, TLR4, IкB $\alpha, p$-IкB $\alpha$ and p-NF- $\kappa B$ p65 normalized to $\beta$-actin. (E) The mRNA expression of TLR2, TLR4 and NF-KB p65. The data are shown as the mean \pm SEM. *, statistical significance $(\mathrm{P}<0.05)$. $* *$, statistical significance $(\mathrm{P}<0.01)$.

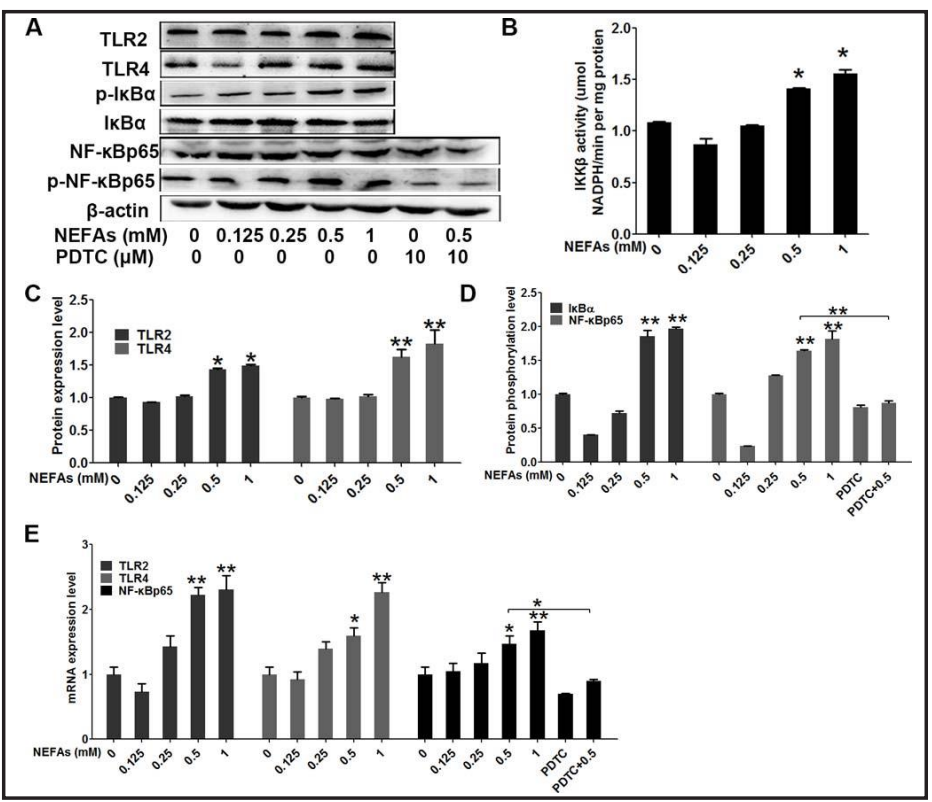
The symbols $*$ and ${ }^{* *}$ indicate significant differences with the control group (no NEFAs and no PDTC), and the two groups that are marked with a horizontal line are significantly different.

3B, D; $P<0.05$ and $P<0.01$ ). The mRNA and phosphorylation levels of NF- $\kappa B$ p65 also increased gradually and were markedly higher in the 0.5 and $1 \mathrm{mM}$ NEFA-treated groups than in the control group (Fig. 3A, D, E; $P<0.05$ and $P<0.01$ ), but they were significantly lower in the PDTC+NEFA-treated group than in the $0.5 \mathrm{mM}$ NEFA-treated group (Fig. 3E, A, $\mathrm{D} ; \mathrm{P}<0.05$ and $\mathrm{P}<0.01)$. Compared with the $0.5 \mathrm{mM}$ NEFA-treated group, the protein levels of TLR2 and TLR4 were significantly lower in the CU-CPT22+NEFA-treated group and the C34+NEFA-treated group than in the 0.5 mM NEFA-treated group (Fig. 4A, B, C, D; P < 0.01). Furthermore, the phosphorylation levels of NF- $\kappa \mathrm{B}$ p 65 were also significantly decreased in the groups treated with an inhibitor of TLR2 and TLR4 (Fig. 4A, B, E, F; P< 0.01). Importantly, we found that NEFA treatment also significantly increased the transcriptional activity of NF$\kappa \mathrm{B}$ p65 in the 0.5 and $1 \mathrm{mM}$ NEFA-treated groups (Fig. $5 ; P<0.01$ ) and were significantly 
Fig. 4. NEFAs activate the TLR2/4$\mathrm{NF}-\kappa \mathrm{B}$ signaling pathway in cow PMNs in vitro. PMNs were treated with $0,0.5$ mM NEFAs, $8 \mu \mathrm{M}$ CUCPT22 + 0.5 mM NEFAs (CUCPT22 + NEFAs) and $10 \mu \mathrm{M} \mathrm{C} 34$ +0.5 mM NEFAs (C34 + NEFAs). (A, B) Western blotting of TLR2, TLR4, NF- $\kappa B$ p65, p-NF- $\kappa B$ p65 and $\beta$-actin. (C-F) Relative protein expression levels of TLR2, TLR4 and $\mathrm{p}-\mathrm{NF}-\kappa \mathrm{Bp} 65$ normalized to $\beta$-actin. The data are shown as the mean \pm SEM. ${ }^{*}$, statistical

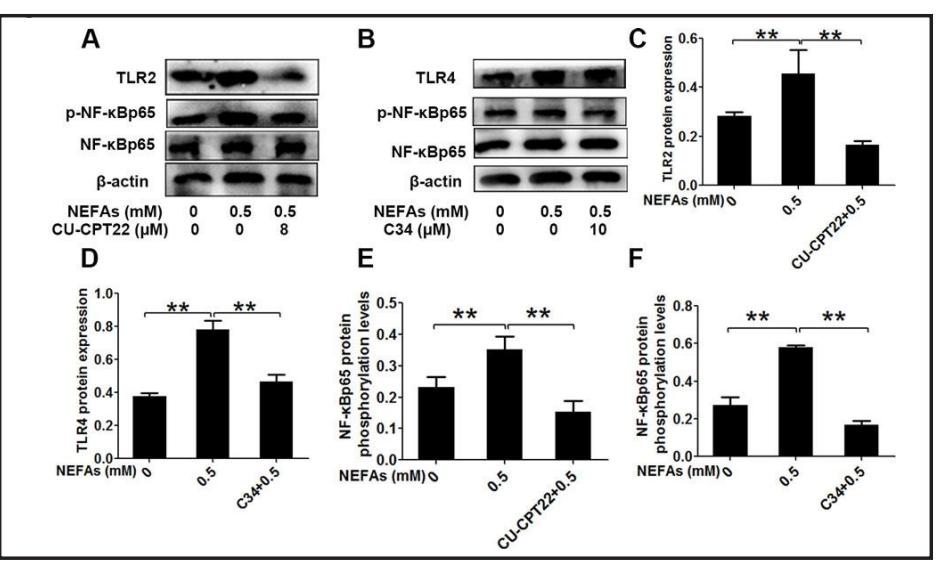
significance $(\mathrm{P}<0.05) . * *$, statistical significance $(\mathrm{P}<0.01)$. The symbols ${ }^{*}$ and ${ }^{* *}$ indicate significant differences with the control group (no NEFAs and no CU-CPT22 or no C34), and two groups that are marked with a horizontal line are significantly different.

Fig. 5. NEFAs increase the transcriptional activity of NF- $\kappa$ B p65. (A) EMSA of NF- $\kappa$ B p65. (B) Relative gray level of NF- $\kappa \mathrm{B}$ p65. The data are shown as the mean \pm SEM. *, statistical significance $(\mathrm{P}<0.05) .{ }^{* *}$, statistical significance $(\mathrm{P}<0.01)$. The symbols $*$ and $* *$ indicate significant differences with the control group (no NEFAs and no PDTC), and two groups that are marked

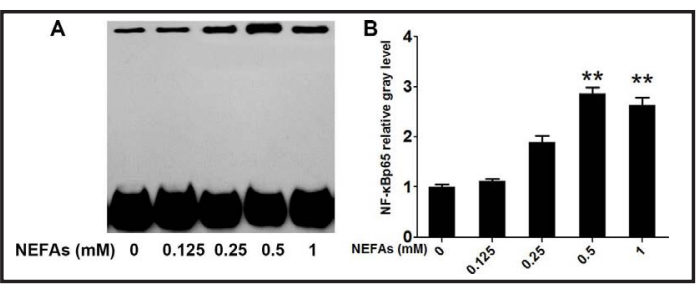
with a horizontal line are significantly different.

Fig. 6. NEFAs increase the expression and synthesis of proinflammatory cytokines in PMNs. PMNs were treated with NEFAs as described in Fig. 3. The cell supernatant was collected to detect the expression of proinflammatory cytokines in cow PMNs. (A) The mRNA levels of IL$1 \beta$. (B) The mRNA levels of IL-6. (C) The mRNA levels of TNF- $\alpha$. (D) The concentrations of IL-1 $\beta$. (E)

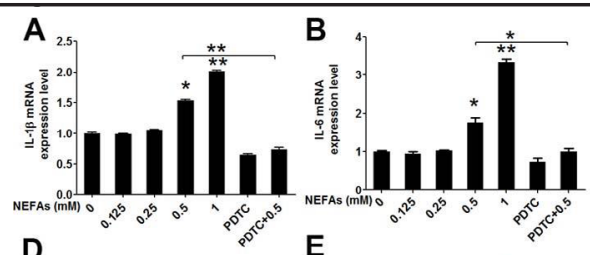

D
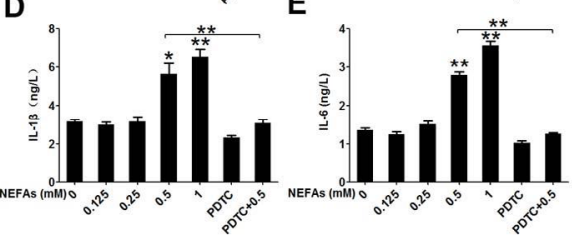

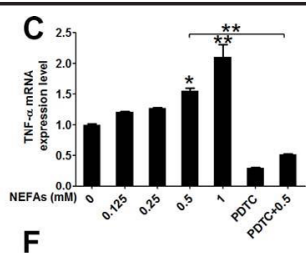

$\mathbf{F}$

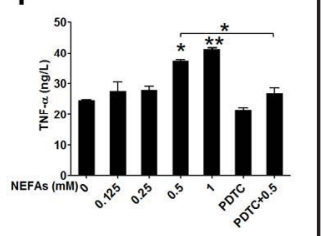

The concentrations of IL- 6 . (F) The

concentrations of TNF- $\alpha$. The data are shown as the mean \pm SEM. *, statistical significance $(\mathrm{P}<0.05)$. ${ }^{* *}$, statistical significance $(\mathrm{P}<0.01)$. The symbols $*$ and ${ }^{* *}$ indicate significant differences with the control group (no NEFAs and no PDTC), and two groups that are marked with a horizontal line are significantly different.

higher in the 0.5 and $1 \mathrm{mM}$ NEFA-treatment groups than in the control group. These results indicate that high concentrations of NEFAs can activate the TLR2/4-NF- $\kappa B$ pathway in cow PMNs.

\section{Effects of NEFAs on the proinflammatory factors $I L-1 \beta, I L-6$, and TNF- $\alpha$ in cow PMNS}

The NF- $\kappa B$ subunit p65 separates from I $\kappa B$ and translocates into the nucleus where $\mathrm{NF}-\kappa \mathrm{B}$ can regulate the transcription of several inflammatory cytokine genes [11]. To further investigate the effect of NEFAs on the NF- $\kappa B$ pathway, the mRNA and protein levels of inflammatory cytokines were detected. As expected, the mRNA levels of IL-1 $\beta$, IL-6, and 


\section{Cellular Physiology Cell Physiol Biochem 2018;48:827-837 \\ \begin{tabular}{c|c} 
DOI: 10.1159/000491913 & Ond Biochemistry \\
Published online: July 20, 2018 & $\begin{array}{l}\text { 2018 The Author(s). Published by S. Karger AG, Basel } \\
\text { www.karger.com/cpb }\end{array}$
\end{tabular} \\ Zhang et al.: Nefas Over-Activate the TLR2/4-NF-KB Signaling Pathway in Neutrophils}

TNF- $\alpha$ were increased in a NEFA-dose-dependent manner and were significantly higher in the 0.5 and $1 \mathrm{mM}$ NEFA-treated groups than in the control group, but showed a decreasing trend in the PDTC+NEFA-treated group compared with the $0.5 \mathrm{mM}$ NEFA-treated group (Fig. $6 \mathrm{~A}, \mathrm{~B}, \mathrm{C} ; P<0.05$ and $P<0.01$ ). The protein levels of IL-1 $\beta$, IL-6, and TNF- $\alpha$ showed a similar trend in cow PMNs (Fig. 6D, E, F; $P<0.05$ and $P<0.01$ ). These results suggest that NEFAs can significantly upregulate the mRNA expression and synthesis of proinflammatory cytokines through the TLR2/4-NF- $\kappa$ B signaling pathway in cow PMNs.

\section{Discussion}

Cows experience a series of nutritional, physiological, and behavioral changes during the transition period and become more susceptible to metabolic and infectious diseases, such as fatty liver, ketosis, mastitis, and metritis [3]. During the early lactation period, most dairy cows experience a negative energy balance caused by the increased demand for energy to support milk production. In this study, we found that dairy cows with clinical ketosis displayed a significant increase in the blood concentrations of NEFAs and BHBA, but a marked decrease in glucose. At the same time, the activity of GLDH, GGT, AST, ALT, and ALP was significantly enhanced in ketotic cows compared with control cows, which is consistent with the results of other studies [16]. These findings indicate that cows with clinical ketosis exhibit hepatic damage.

NEFAs are a crucial source of energy in the liver and peripheral tissues. However, high levels of NEFAs, a pathological factor of ketosis, induce lipotoxicity and can impair cellular metabolic function and activate inflammatory pathways [17]. Many diseases that occur during the perinatal period, including mastitis and metritis, are related to elevated concentrations of NEFAs in dairy cows $[7,8,18]$. In the present study, we found that the blood concentrations of the proinflammatory cytokines IL-1 $\beta$, IL-6, and TNF- $\alpha$ were significantly increased in ketotic cows and had a positive relationship with the concentrations of NEFAs. These results indicate that cows with clinical ketosis exhibit a strong inflammatory response, which may be related to high blood levels of NEFAs.

Neutrophils play a crucial role in the defense against infection [19]. Furthermore, dairy cows with ketosis displayed high levels of IL- $1 \beta$, IL-6, and TNF- $\alpha$. Accordingly, we speculated that high levels of NEFAs could induce the over-production of proinflammatory factors by PMNs in cows with clinical ketosis. Therefore, in vitro, cultured PMNs were treated with different concentrations of NEFAs, and the mRNA and protein levels of IL-1 $\beta$, IL- 6 , and TNF- $\alpha$ were determined by qRT-PCR and ELISA, respectively. The results showed that high levels of NEFAs could also significantly increase the expression and release of IL-1 $\beta$, IL- 6 , and TNF- $\alpha$. This indicates that high levels of NEFAs may act as important inflammatory mediators and over-induce the synthesis of inflammatory cytokines in PMNs from cows. A clinical study reported that a number of inflammation-related genes, including IL-1 receptor type II, TNF receptor superfamily member 25 , and IL-6, were significantly increased in cows with nutrition-induced ketosis compared to control Holstein cows [20,21], which further support our hypothesis.

TLRs, including TLR2 and TLR4, are most highly expressed in neutrophils and macrophages and play direct roles in innate immune responses [22]. Senn demonstrated that TLR2 is essential for the production of IL- 6 during palmitate-induced insulin resistance in myotubes [23]. Importantly, several laboratories have independently reported that the proinflammatory effects of saturated fatty acids are mediated, at least in part, through the activation of TLR4 and/or TLR2 [24, 25]. Furthermore, TLR4-deficient mice are protected from the inflammatory activation induced by obesity and a high-fat diet [10]. These studies demonstrated that TLR-mediated pathways play an important role in metabolic signalassociated inflammation. In our study, the mRNA and protein levels of TLR2 and TLR4 were significantly increased in PMNs from cows with clinical ketosis. Importantly, treatment with NEFAs also induced the over-expression of TLR2 and TLR4 in PMNs. These results obtained 


\section{Cellular Physiology Cell Physiol Biochem 2018;48:827-837 \begin{tabular}{l|l} 
DOI: 10.1159/000491913 & $\begin{array}{l}\text { O } 2018 \text { The Author(s). Published by S. Karger AG, Basel } \\
\text { www.karger.com/cpb }\end{array}$
\end{tabular} \\ Zhang et al.: Nefas Over-Activate the TLR2/4-NF-кB Signaling Pathway in Neutrophils}

in vivo and in vitro indicate that the high expression of TLR2 and TLR4 may mediate the NEFA-induced over-production of inflammatory cytokines.

The intracellular signals downstream of TLR activation are propagated via the NF- $\kappa B$ pathway, which is an important redox-sensitive and proinflammatory transcription factor that plays a critical role in the regulation of a variety of genes involved in the inflammatory response [26]. The most classical NF- $\kappa B$ binding form is $\mathrm{p} 65$, which remains associated with the I $\kappa$ B family of inhibitory proteins in the cytoplasm before activation [27]. The cytoplasmic $\mathrm{NF}-\kappa \mathrm{B} / \mathrm{I} \kappa \mathrm{B}$ complex is phosphorylated on conserved serine residues of I $\mathrm{B}$, which leads to the dissociation of I $\kappa B$ from NF- $\kappa B$ and the subsequent translocation of NF- $\kappa B$ p 65 to the nucleus. After tyrosine phosphorylation, NF- $\kappa \mathrm{B}$ p65 binds to its cognate DNA-binding site in the promoter regions of specific genes, such as TNF- $\alpha$, IL-6, and IL-1 $\beta[28,29]$.

In this study, the phosphorylation levels of NF- $\kappa B$ p65, I $\kappa B \alpha$, and IKK $\beta$ were significantly increased in PMNs from ketotic cows. In vitro, NEFA treatment also significantly induced the over-activation of this pathway in PMNs. Additionally, the transcriptional activity of NF- $\kappa B$ p65 also increased in response to NEFA treatment. Importantly, the inhibition of NF$\kappa B$ p65 by PDTC could significantly decrease the mRNA and protein expression of TNF- $\alpha$, IL-6, and IL-1 $\beta$ induced by NEFA treatment. Taken together, our in vivo and in vitro results indicate that NEFAs can induce the over-activation of the TLR-NF- $\kappa B$ pathway and promote the expression of IL-1 $\beta$, IL-6, and TNF- $\alpha$ in PMNs. Increasing evidence has demonstrated that high concentrations of fatty acids, such as lauric acid, palmitic acid, or stearic acid [30], can activate TLR2 and TLR4 and induce inflammation effectively, which further supports our results. Dairy cows with clinical ketosis displayed high blood concentrations of NEFAs. Importantly, high levels of NEFAs induced the over-production of inflammatory cytokines in cows with ketosis, which aggravated the inflammatory status of the cows and made them more susceptible to mastitis and metritis.

\section{Conclusion}

In summary, dairy cows with ketosis are characterized by a negative energy balance and high blood levels of NEFAs, which over-activate the TLR-NF- $\kappa B$ pathway and promote the expression and synthesis of IL-1 $\beta$, IL-6, and TNF- $\alpha$ in PMNs, thereby increasing inflammation in ketotic cows.

\section{Acknowledgements}

This work was supported by the National key research and development program (Beijing, China; grant no. 2016YFD0501206), National Natural Science Foundation of China (Beijing, China; grant nos. 31372494, 31672621, 31572581, and 31772810), and the Natural Science Foundation of Jilin Province (Changchun, China; grant no. 20170101148JC).

\section{Disclosure Statement}

Thea authors declare to have no competing interests.

\section{References}

1 Goff JP: Major advances in our understanding of nutritional influences on bovine health. J Dairy Sci 2006;89:1292-1301.

2 Sordillo LM, Raphael W: Significance of metabolic stress, lipid mobilization, and inflammation on transition cow disorders. Vet Clin Food Anim 2013;29:267-278. 


\section{Cellular Physiology Cell Physiol Biochem 2018;48:827-837 \begin{tabular}{l|l} 
DOI: 10.1159/000491913 & $\begin{array}{l}\text { O } 2018 \text { The Author(s). Published by S. Karger AG, Basel } \\
\text { www.karger.com/cpb }\end{array}$
\end{tabular} \\ Zhang et al.: Nefas Over-Activate the TLR2/4-NF-kB Signaling Pathway in Neutrophils}

- 3 Goff JP, Horst RL: Physiological changes at parturition and their relationship to metabolic disorders. J Dairy Sci 1997;80:1260-1268.

4 Min Zhang, Shiqi Zhang, Qi Hui, Lin Lei, Xiliang Du, Wenwen Gao, Renhe Zhang, Guowen Liu, Xiaobing Li, Xinwei Li: $\beta$-Hydroxybutyrate Facilitates Fatty Acids Synthesis Mediated by Sterol Regulatory ElementBinding Protein1 in Bovine Mammary Epithelial Cells. Cell Physiol Biochem 2015;37:2115-2124 Duffield T, Herdt TH: Subclinical ketosis in lactating dairy cattle. Vet Clin Food Anim 2000;16:231-253. Leblanc SJ, Osawa T, Dubuc J: Reproductive tract defense and disease in postpartum dairy cows. Theriogenology 2011;76:1610-1618.

7 Hammon DS, Evjen IM, Dhiman TR, Goff JP, Walters JL: Neutrophil function and energy status in holstein cows with uterine health disorders. Vet Immunol Immunopathol 2006;113:21-29.

$>8$ Zhang G, Hailemariam D, Dervishi E, Goldansaz SA, Deng Q Dunn SM, Ametaj BN: Dairy cows affected by ketosis show alterations in innate immunity and lipid and carbohydrate metabolism during the dry off period and postpartum. Res Vet Sci 2016;107:246-256.

-9 Lee JY, Hwang DH: The modulation of inflammatory gene expression by lipids: Mediation through toll-like receptors. Mol Cells 2006; 21:174-185.

10 Shi H, Kokoeva MV, Inouye K, Tzameli I, Yin H, Flier JS: TLR4 links innate immunity and fatty acid-induced insulin resistance. The Journal of Clinical Investigation 2006;116:3015-3025.

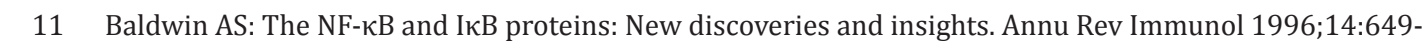
683.

12 Behrendt JH, Ruiz A, Zahner H, Taubert A, Hermosilla C: Neutrophil extracellular trap formation as innate immune reactions against the apicomplexan parasite eimeria bovis. Vet Immunol Immunopathol 2010;133:1-8.

13 Du, X., Y. Zhu, Z. Peng, Y. Cui, Q. Zhang, Z. Shi, Y. Guan, X. Sha, T. Shen, Y. Yang, X. Li, Z. Wang, X. Li, and G. Liu: High concentrations of fatty acids and beta-hydroxybutyrate impair the growth hormone-mediated hepatic JAK2-STAT5 pathway in clinically ketotic cows. J Dairy Sci 2018, 101:3476-3487

14 Yamdagni S, Schultz L H: Fatty acid composition of blood plasma lipids of normal and ketotic cows. J Dairy Sci 1970, 53:1046-1050.

15 Stich V, Berlan M: Physiological regulation of NEFA availability: Lipolysis pathway. Proc Nutr Soc 2004;63:369-374.

16 Xiliang Du, Liang Chen, Dan Huang, Zhicheng Peng, Chenxu Zhao, Yuming Zhang, Yiwei Zhu, Zhe Wang, Xinwei Li, Guowen Liu: Elevated Apoptosis in the Liver of Dairy Cows with Ketosis. Cell Physiol Biochem 2017;43:568-578.

17 Xiaoxia Shi, Dangdang Li, Qinghua Deng, Yu Li, Guoquan Sun, Xue Yuan, Yuxiang Song, Zhe Wang, Xiaobing $\mathrm{Li}$, Xinwei Li, Guowen Liu: NEFAs activate the oxidative stress-mediated NF- $\kappa \mathrm{B}$ signaling pathway to induce inflammatory response in calf hepatocytes. J Steroid Biochem Mol Biol 2014;145:103-112.

18 Lacetera N, Franci O, Scalia D, Bernabucci U, Ronchi B, Nardone A: Effects on functions of ovine blood mononuclear cells for each of several fatty acids at concentrations found in plasma of healthy and ketotic ewes. Am J Vet Res 2005;63:958-962.

19 Burg ND, Pillinger MH: The neutrophil: Function and regulation in innate and humoral immunity. Clin Immunol 2001;99:7-17.

-20 Loor JJ, Everts RE, Bionaz M, Dann HM, Morin DE, Oliveira R, Rodriguezzas SL, Drackley JK, Lewin HA: Nutrition-induced ketosis alters metabolic and signaling gene networks in liver of periparturient dairy cows. Physiol Genomics 2007;32:105-116.

21 Moyes KM, Drackley JK, Morin DE, Loor JJ: Greater expression of TLR2, TLR4, and IL6 due to negative energy balance is associated with lower expression of HLA-DRA and HLA-A in bovine blood neutrophils after intramammary mastitis challenge with streptococcus uberis. Funct Integr Genomics 2010;10:53-61.

22 Iwasaki A, Medzhitov R: Control of adaptive immunity by the innate immune system. Nat. Immunol 2015;16:343-353.

23 Senn JJ: Toll-like receptor-2 is essential for the development of palmitate-induced insulin resistance in myotubes. J Biol Chem 2006;281:26865-26875.

24 Schaeffler A, Gross P, Buettner R, Bollheimer C, Buechler C, Neumeier M, Kopp A, Schoelmerich J, Falk $\mathrm{W}$ : Fatty acid-induced induction of Toll-like receptor-4/nuclear factor- $\kappa \mathrm{B}$ pathway in adipocytes links nutritional signalling with innate immunity. Immunology 2009;126:233-245. 


\section{Cellular Physiology Cell Physiol Biochem 2018;48:827-837

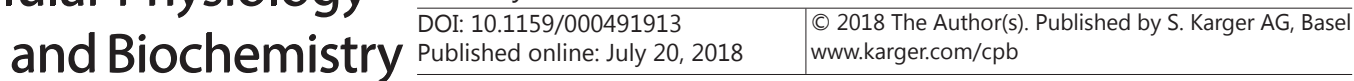

-25 Erridge C, Samani NJ: Saturated fatty acids do not directly stimulate Toll-like receptor signaling. Arterioscler Thromb Vasc Biol 2009;29:1944-1949.

-26 Zhang Y, Lu Y, Li M, Cao X, Xiao J, Chen J, Jiao S, Gao Y, Liu C, Duan Z: Activation of vascular endothelial growth factor receptor-3 in macrophages restrains TLR4-NF- $\mathrm{BB}$ signaling and protects against endotoxin shock. Immunity 2014;40:501-514.

27 Siomek A: NF- $\kappa$ B signaling pathway and free radical impact. Acta Biochim Pol 2012;59:323-331.

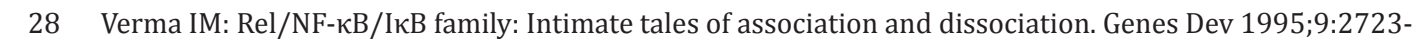
2735.

29 Xudong Sun, Xue Yuan, Liang Chen, Tingting Wang, Zhe Wang, Guoquan Sun, Xiaobing Li, Xinwei Li, Guowen Liu: Histamine Induces Bovine Rumen Epithelial Cell Inflammatory Response via NF- $\kappa$ B Pathway. Cell Physiol Biochem 2017;42:1109-1119.

30 Schwartz EA, Zhang WY, Karnik SK, Borwege S, Anand VR, Laine PS, Su Y, Reaven PD: Nutrient modification of the innate immune response a novel mechanism by which saturated fatty acids greatly amplify monocyte inflammation. Arterioscler Thromb Vasc Biol 2010;30:802-808. 